\title{
PENGETAHUAN TENTANG PENYEBAB DAN DAMPAK KEHILANGAN GIGI TERHADAP KEJADIAN KEHILANGAN GIGI PADA LANSIA
}

\author{
Lelli Adi Wahyuni ${ }^{1}$, Vitri Nurilawaty ${ }^{2}$, Rini Widiyastuti ${ }^{3}$, Tedi Purnama ${ }^{4}$ \\ 1,2,3,4 Jurusan Keperawatan Gigi, Politeknik Kesehatan Kemenkes Jakarta I, Indonesia
}

\begin{tabular}{ll}
\hline Info Artikel & Abstrak \\
\hline Genesis Naskah: & $\begin{array}{l}\text { Latar belakang: Penyakit di rongga mulut pada lansia dapat berakibat negatif terhadap } \\
\text { kesehatan dan kualitas hidup lansia secara keseluruhan. Beberapa kondisi yang sering terjadi }\end{array}$ \\
Submitted: $2021-08-28$ & $\begin{array}{l}\text { pada rongga mulut lansia yaitu kehilangan gigi, penyakit gusi, mulut kering/xerostomia, dan } \\
\text { periodontitis. Kehilangan gigi merupakan penyebab terbanyak menurunnya fungsi } \\
\text { pengunyahan. Tujuan: Penelitian ini bertujuan untuk mengetahui gambaran pengetahuan }\end{array}$ \\
Revised: $2021-09-24$ & tentang penyebab dan dampak kehilangan gigi terhadap kejadian kehilangan gigi pada lansia. \\
Accepted: $2021-09-27$ & Metode: Penelitian ini menggunakan metode deskriptif dengan teknik pengambilan sampling \\
\hline Kata Kunci: & menggunakan purposive sampling. Pengumpulan data dilakukan dengan melakukan observasi \\
Pengetahuan Penyebab dan & kehilangan gigi dan lembar kuesioner. Hasil: Hasil penelitian ini menunjukkan persentase \\
Dampak, Lansia, & pengetahuan responden tentang penyebab kehilangan gigi paling banyak dengan kategori \\
Kehilangan Gigi & kurang (70\%), pengetahuan tentang dampak kehilangan gigi paling banyak dengan kategori \\
& kurang (50\%), jumlah lansia yang kehilangan gigi lebih banyak yaitu sebanyak 10 orang \\
& kehilangan gigi pada lansia yaitu 6-10 gigi yang hilang (33,3\%), pengetahuan tentang penyebab \\
& kehilangan gigi terhadap kejadian kehilangan gigi paling tinggi yaitu kategori kurang (26,7\%), \\
& dan pengetahuan tentang dampak kehilangan gigi terhadap kejadian kehilangan gigi paling \\
tinggi yaitu kategori kurang (26,7\%). Kesimpulan: pengetahuan tentang penyebab dan dampak & kehilangan terhadap kejadian kehilangan gigi pada lansia di Majelis Taklim Baiturrohim Desa \\
& Cimanggu Pandeglang tahun 2021 termasuk dalam kategori kurang.
\end{tabular}

KNOWLEDGE ABOUT CAUSES AND IMPACTS OF TOOTH LOSS ON THE INCIDENCE OF TOOTH LOSS IN THE ELDERLY

\begin{tabular}{ll}
\hline Keywords: & Abstract \\
Knowledge Cause and & Background: All humans will get old age and getting old is a natural process that cannot be \\
Impact, Elderly, Tooth Loss & avoided by every living being. Diseases in the oral cavity in the elderly can negatively affect the \\
health and quality of life of the elderly as a whole. Some conditions that often occur in the & elderly mouth namely tooth loss, gum disease, dry mouth/xerostomia, and periodontitis. Tooth \\
loss is the main cause of decreased chewing function. Tooth loss can also affect the oral cavity \\
and general health so it will affect a person's overall quality of life. Objective: The purpose of \\
this research is to describe the knowledge about the causes and impacts of tooth loss on the \\
incidence off tooth loss in the elderly in Taklim Baiturrohim Assembly Cimangu Village \\
Pandeglang in 2021. Method: This research used a descriptive method using purposive \\
sampling technique. Data accumulation was conducted by examination, interviews, and filling \\
out questionnaire sheet. The instruments that used are examination sheets and questionnaire \\
sheets. Result : The result of this research showed the percentage of respondents knowledge \\
about causes of tooth loss is the most in the less category (70\%), knowledge about the impact \\
of tooth loss is the most in the less category (50\%), tooth loss in the elderly which is 6-10 missing \\
teeth, knowledge about the causes of tooth loss the highest incidence of tooth loss was in the \\
less category (26,7\%), and knowledge about the impact of tooth loss the highest incidence of \\
tooth loss was in the less category (26,7\%). Conclusion: Knowledge of the causes and impacts \\
of tooth loss in the elderly in the Taklim Baiturrohim Assembly of Cimanggu Village Pandeglang \\
in 2021 belonged to less category.
\end{tabular}

\footnotetext{
Korespondensi Penulis:

Lelli Adi Wahyuni

Kp. Cimanggu, Ds. Cimanggu, Ke. Cimanggu, Pandeglang - Banten

Email: lelliadiwahyuni@gmail.com
}

C J Jurusan Keperawatan Gigi Poltekkes Kemenkes Jakarta I Jl. Wijaya Kusuma No. 47-48 Cilandak Jakarta Selatan, Indonesia email: jdht@poltekkesjakarta1.ac.id 


\section{Pendahuluan}

Semua manusia akan mengalami masa lansia dan menjadi tua adalah proses alami yang tidak dapat dihindari oleh setiap makhluk hidup, proses ini akan berjalan secara terus menerus seiring berjalannya perjalanan kehidupan. Menurut Undang-Undang Republik Indonesia No. 13 Tahun 1998 pasal 1 ayat 2 tentang kesejahteraan lansia, lanjut usia adalah seseorang yang telah mencapai usia 60 tahun (enam puluh) tahun keatas (Rezaaziza, 2021).

Akibat bertambahnya usia secara berangsurangsur gigi berkurang karena tanggal. Ketidaklengkapan gigi tentunya akan dapat mengurangi kenyamanan makan dan membatasi jenis-jenis makanan yang dikonsumsi. Kurang menjaga kebersihan gigi bisa berimplikasi masuknya bakteri yang berujung pada banyak masalah kesehatan yang umum seperti penyakit jantung dan penyakit lainnya. Penyakit di rongga mulut pada lansia dapat berakibat negatif terhadap kesehatan dan kualitas hidup lansia secara keseluruhan. Beberapa kondisi yang sering terjadi pada rongga mulut lansia yaitu kehilangan gigi, penyakit gusi, mulut kering/xerostomia, dan periodontitis (Senjaya, 2016)

Kehilangan gigi merupakan penyebab terbanyak menurunnya fungsi pengunyahan. Kehilangan gigi juga dapat mempengaruhi rongga mulut dan kesehatan umum sehingga akan mempengaruhi kualitas hidup seseorang secara keseluruhan. Kehilangan gigi dapat disebabkan oleh berbagai hal, penyebab terbanyak kehilangan gigi adalah akibat buruknya status kesehatan rongga mulut, terutama karies dan penyakit periodontal (Ratmini \& Arifin, 2011)

Terjadinya kehilangan gigi dapat mempengaruhi struktur orofasial, seperti jaringan tulang, persarafan, otot-otot, dan berkurangnya fungsi orofasial. Selain itu juga, mukosa rongga mulut akan mengalami perubahan pada struktur, fungsi, dan juga elastisitas jaringan mukosa rongga mulut. Kehilangan gigi dapat terjadi karena adanya interaksi faktor kompleks seperti karies, penyakit periodontal, dan trauma, serta kasus yang paling sering terjadi diakibatkan karena adanya karies (Rizkillah et al., 2019)

Kehilangan gigi disebut juga edentulous. Kehilangan gigi dapat didefinisikan sebagai hilangnya beberapa atau semua gigi pada lengkung rahang. Hilangnya gigi akan menyebabkan penurunan tulang alveolar, migrasi gigi tetangga serta dapat mempengaruhi jaringan pendukung dalam menerima retorasi prostetik yang adekuat (Anshary, Cholil,

(C) Jurusan Keperawatan Gigi Poltekkes Kemenkes Jakarta I J1. Wijaya Kusuma No. 47-48 Cilandak Jakarta Selatan, Indonesia email: jdht@poltekkesjakarta1.ac.id
2014). Kehilangan gigi dapat diklasifikasikan sebagai masalah rongga mulut. Penyebab kehilangan gigi geligi sering disebabkan oleh faktor penyakit seperti karies dan penyakit periodontal. Faktor lain seperti trauma, sikap dan karakteristik terhadap pelayanan kesehatan gigi, faktor sosio demografi serta gaya hidup juga turut mempengaruhi hilangnya gigi (Senjaya, 2016).

Kehilangan gigi yang dibiarkan terlalu lama akan menyebabkan migrasi patologis gigi geligi yang tersisa, penurunan tulang alveolar pada daerah yang edentulous, penurunan fungsi pengunyahan hingga gangguan berbicara dan juga dapat berpengaruh terhadap sendi temporomandibular. Karena idealnya oklusi yang baik harus memungkinkan mandibula bertranslasi tanpa hambatan oklusal saat terjadi gerakan fungsional terutama pada segmen posterior sehingga distribusi beban lebih merata (Satria Wardhana et al., 2015).

Berdasarkan penelitian Rezaaziza (2020) tentang Gambaran Pengetahuan Warga Lansia Tentang Faktor Penyebab dan Dampak Kehilangan Gigi Tahun 2020 menunjukkan bahwa persentase pengetahuan responden tentang faktor penyebab dan dampak kehilangan gigi sebesar pada 20 warga lansia berusia 65-74 tahun 33\%. Kesimpulan penelitian ini adalah pengetahuan warga lansia di Posyandu Lansia Desa Wonocoyo Kecamatan Panggul Kabupaten Trenggalek tentang faktor penyebab dan dampak kehilangan gigi tahun 2020 termasuk dalam kategori kurang.

Penelitian Noviani et al. (2020) tentang Kehilangan Gigi Pada Ibu Usia 30-60 Tahun Di Pengajian Karang Tengah Rt 005/03 Lebak Bulus Cilandak Jakarta Selatan menunjukkan bahwa hasil penelitian diperoleh responden yang memiliki kehilangan gigi $\leq 3$ gigi sebanyak 30 orang $(75 \%)$ sedangkan kehilangan gigi $>3$ gigi sebanyak 10 orang (25\%). Responden pada kelompok umur 45-60 tahun memiliki kehilangan gigi lebih tinggi daripada kelompok umur 30-45 tahun.

Berdasarkan uraian diatas peneliti tertarik untuk melakukan penelitian tentang gambaran pengetahuan tentang penyebab dan dampak kehilangan gigi terhadap kejadian kehilangan gigi pada lansia.

\section{Metode}

Jenis penelitian ini menggunakan metode penelitian deskriptif yaitu untuk mengetahui gambaran pengetahuan tentang penyebab dan dampak kehilangan gigi terhadap kejadian kehilangan gigi

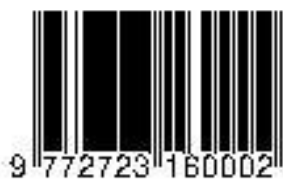


pada lansia di Majelis Taklim. Teknik pengambilan sampel menggunakan teknik purposive sampling yaitu sebanyak 30 responden.

Penelitian ini dilakukan pada bulan Mei tahun 2021 menggunakan data primer yang diambil secara langsung oleh peneliti. Pelaksanaan pengambilan data di masa pandemi covid-19 peneliti menerapkan protokol kesehatan yang ketat menggunakan APD level 2 dengan mendatangi responden dari rumah ke rumah. Instrument yang digunakan adalah kuesioner untuk mengukur pengetahuan tentang penyebab dan dampak kehilangan gigi serta lembar observasi untuk mengetahui jumlah kehilangan gigi. Penelitian ini diolah dan dianalisa dalam program excel dan disajikan dalam bentuk distribusi frekuensi.

Hasil

Tabel 1. Distribusi Karakteristik Kehilangan Gigi Berdasarkan Usia

\begin{tabular}{cccc}
\hline No & $\begin{array}{c}\text { Kelompok Usia } \\
\text { Lansia }\end{array}$ & (n) & $(\boldsymbol{\%})$ \\
\hline $\mathbf{1}$ & $45-59$ tahun & 0 & 0 \\
\hline $\mathbf{2}$ & $60-69$ tahun & 22 & 73,3 \\
\hline $\mathbf{3}$ & $\geq 70$ tahun & 8 & 26,7 \\
\hline & Jumlah & 30 & 100
\end{tabular}

Tabel 1 menunjukkan bahwa karakteristik kehilangan gigi berdasarkan usia pada lansia pada 30 orang lansia yaitu berdasarkan kelompok usia 45-59 tahun tidak ada, 60-69 tahun sebanyak 22 orang $(73,3 \%)$, dan $\geq$ 70 tahun sebanyak 8 orang $(26,7 \%)$.

Tabel 2. Distribusi Frekuensi Pengetahuan Tentang Penyebab Kehilangan Gigi

\begin{tabular}{cccc}
\hline No & $\begin{array}{c}\text { Kriteria } \\
\text { Pengetahuan }\end{array}$ & $\begin{array}{c}\text { Jumlah } \\
(\mathbf{n})\end{array}$ & $\begin{array}{c}\text { Persentase } \\
(\mathbf{\%})\end{array}$ \\
\hline $\mathbf{1}$ & Baik & 1 & $3,3 \%$ \\
\hline $\mathbf{2}$ & Cukup & 8 & $26,7 \%$ \\
\hline $\mathbf{3}$ & Kurang & 21 & $70 \%$ \\
\hline & Jumlah & $\mathbf{3 0}$ & $\mathbf{1 0 0 \%}$ \\
\hline
\end{tabular}

Tabel 2 menunjukkan bahwa pengetahuan tentang penyebab kehilangan gigi pada 30 orang lansia yaitu kategori baik sebanyak 1 orang $(3,3 \%)$, kategori cukup sebanyak 8 orang $(26,7 \%)$, dan kategori kurang sebanyak 21 orang $(70 \%)$.

(c) Jurusan Keperawatan Gigi Poltekkes Kemenkes Jakarta I Jl. Wijaya Kusuma No. 47-48 Cilandak Jakarta Selatan, Indonesia email: jdht@poltekkesjakarta1.ac.id
Tabel 3. Distribusi Frekuensi Pengetahuan Tentang Dampak Kehilangan Gigi

\begin{tabular}{cccc}
\hline No & $\begin{array}{c}\text { Kriteria } \\
\text { Pengetahuan }\end{array}$ & $\begin{array}{c}\text { Jumlah } \\
(\mathbf{n})\end{array}$ & $\begin{array}{c}\text { Persentase } \\
(\mathbf{\%})\end{array}$ \\
\hline $\mathbf{1}$ & Baik & 3 & $10 \%$ \\
\hline $\mathbf{2}$ & Cukup & 12 & $40 \%$ \\
\hline $\mathbf{3}$ & Kurang & 15 & $50 \%$ \\
\hline & Jumlah & $\mathbf{3 0}$ & $\mathbf{1 0 0 \%}$ \\
\hline
\end{tabular}

Tabel 3 menunjukkan bahwa pengetahuan tentang dampak kehilangan gigi pada 30 orang lansia yaitu kategori baik sebanyak 3 orang (10\%), cukup sebanyak 12 orang $(40 \%)$, dan kurang sebanyak 15 orang $(50 \%)$.

Tabel 4. Distribusi Frekuensi Kehilangan Gigi

\begin{tabular}{ccccc}
\hline No & Kriteria & (n) & $\begin{array}{c}\text { Jumlah } \\
\text { Gigi } \\
\text { Hilang }\end{array}$ & $(\%)$ \\
\hline 1 & $\begin{array}{c}\text { Tidak Ada } \\
\text { Gigi Hilang }\end{array}$ & 2 & 0 & $6,7 \%$ \\
\hline 2 & $\begin{array}{c}\text { Kehilangan } \\
\text { Gigi < 6 gigi }\end{array}$ & 10 & 33 & $33,3 \%$ \\
\hline 3 & $\begin{array}{c}\text { Kehilangan } \\
\text { Gigi 6-10 gigi }\end{array}$ & 10 & 74 & $33,3 \%$ \\
\hline 4 & $\begin{array}{c}\text { Kehilangan } \\
\text { Gigi > 10 gigi }\end{array}$ & 8 & 112 & $26,7 \%$ \\
\hline & Jumlah & $\mathbf{3 0}$ & $\mathbf{2 1 9}$ & $\mathbf{1 0 0 \%}$ \\
\hline
\end{tabular}

Tabel 4 menunjukkan bahwa dari 30 responden yang sudah dilakukan pemeriksaan kehilangan giginya. Maka didapatkan bahwa terdapat 2 orang yang tidak ada gigi hilang dalam mulutnya $(6,7 \%), 10$ orang kehilangan gigi kurang dari 6 gigi $(33,3 \%), 10$ orang kehilangan gigi $6-10$ gigi $(33,3 \%)$, dan 8 orang kehilangan gigi lebih dari 10 gigi $(26,7 \%)$. Total gigi yang hilang pada lansia peserta pengajian di Majelis Taklim Baiturrohim Desa Cimanggu Pandeglang yaitu 219 gigi yang hilang.

Tabel 5. Distribusi Frekuensi Pengetahuan Tentang Penyebab Kehilangan Gigi Terhadap Kejadian Kehilangan Gigi

\begin{tabular}{|c|c|c|c|c|c|c|c|c|c|c|}
\hline \multirow{3}{*}{$\begin{array}{c}\text { Pengeta } \\
\text { huan }\end{array}$} & \multicolumn{8}{|c|}{ Gigi Hilang } & \multirow{2}{*}{\multicolumn{2}{|c|}{ Jumlah }} \\
\hline & \multicolumn{2}{|c|}{$\begin{array}{c}\text { Tidak } \\
\text { Ada } \\
\end{array}$} & \multicolumn{2}{|c|}{$<6$} & \multicolumn{2}{|c|}{$6-10$} & \multicolumn{2}{|c|}{$>10$} & & \\
\hline & $\mathbf{n}$ & $\%$ & $\mathbf{n}$ & $\%$ & $\mathbf{n}$ & $\%$ & $\mathbf{n}$ & $\%$ & $\mathbf{n}$ & $\%$ \\
\hline Baik & 1 & 3,3 & 2 & 6,7 & 0 & 0 & 0 & 0 & 3 & 10 \\
\hline Cukup & 1 & 3,3 & 5 & 16,7 & 2 & 6,7 & 3 & 10 & 11 & 36,7 \\
\hline Kurang & 0 & 0 & 3 & 10 & 8 & 26,7 & 5 & 16,6 & 16 & 53,3 \\
\hline Jumlah & 2 & 6,6 & 10 & 33,4 & 10 & 33,4 & 8 & 26,6 & 30 & 100 \\
\hline
\end{tabular}

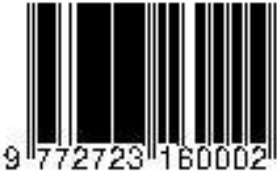


Tabel 5 menunjukkan bahwa pengetahuan tentang penyebab kehilangan gigi terhadap kejadian kehilangan gigi pada lansia paling tinggi yaitu kategori kurang sebanyak 8 orang $(26,7 \%)$ dengan jumlah kehilangan gigi 6-10 gigi, dan paling rendah yaitu kategori baik sebanyak 1 orang $(3,3 \%)$ dengan jumlah kehilangan gigi $<6$ gigi yang hilang.

Tabel 6. Distribusi Frekuensi Pengetahuan Tentang Dampak Kehilangan Gigi Terhadap Kejadian Kehilangan Gigi

\begin{tabular}{|c|c|c|c|c|c|c|c|c|c|c|}
\hline \multirow{3}{*}{$\begin{array}{c}\text { Pengeta } \\
\text { huan }\end{array}$} & \multicolumn{8}{|c|}{ Gigi Hilang } & \multirow{2}{*}{\multicolumn{2}{|c|}{ Jumlah }} \\
\hline & \multicolumn{2}{|c|}{$\begin{array}{c}\text { Tidak } \\
\text { Ada }\end{array}$} & \multicolumn{2}{|c|}{$<6$} & \multicolumn{2}{|c|}{$6-10$} & \multicolumn{2}{|c|}{$>10$} & & \\
\hline & $\mathbf{n}$ & $\%$ & $\mathbf{n}$ & $\%$ & $\mathbf{n}$ & $\%$ & $\mathbf{n}$ & $\%$ & $\mathbf{n}$ & $\%$ \\
\hline Baik & 0 & 0 & 1 & 3,3 & 0 & 0 & 0 & 0 & 1 & 3,3 \\
\hline Cukup & 1 & 3,3 & 4 & 13,3 & 2 & 6,7 & 1 & 3,3 & 8 & 26,7 \\
\hline Kurang & 1 & 3,3 & 5 & 16,7 & 8 & 26,7 & 7 & 23,4 & 21 & 70 \\
\hline Jumlah & 2 & 6,6 & 10 & 33,3 & 10 & 33,4 & 8 & 26,7 & 30 & 100 \\
\hline
\end{tabular}

Tabel 6 menunjukkan bahwa pengetahuan dampak kehilangan gigi terhadap kejadian kehilangan gigi pada lansia paling tinggi yaitu kategori kurang sebanyak 8 orang $(26,7 \%)$ dengan jumlah kehilangan gigi 6-10 gigi yang hilang, dan paling rendah yaitu dengan kategori baik sebanyak 1 orang $(3,3 \%)$ dengan tidak ada gigi yang hilang.

\section{Pembahasan}

Data yang didapatkan berdasarkan hasil penelitian yang telah dilakukan pada lansia di Majelis Taklim Baiturrohim Desa Cimanggu Pandeglang tahun 2021 dengan jumlah 30 orang lansia menunjukkan bahwa hasil penelitian terhadap karakteristik kehilangan gigi berdasarkan usia menunjukkan paling banyak yaitu kelompok usia 6069 tahun sebanyak 22 orang $(73,3 \%)$. Penelitian diatas tidak sejalan dengan penelitian (Rizkillah et al., 2019), dalam penelitiannya yang berjudul pengaruh kehilangan gigi posterior terhadap kualitas hidup pada kelompok usia 45-65 tahun menyatakan bahwa Karakteristik responden berdasarkan usia yang paling banyak adalah usia 51 - 60 tahun sebanyak 38 orang $(49,3 \%)$. Hal ini kemungkinan dipengaruhi oleh proses penuaan dan faktor-faktor seperti karies, penyakit periodontal, dan trauma yang dapat menyebabkan kehilangan gigi. Penyebab kehilangan gigi geligi sering disebabkan oleh faktor penyakit seperti karies dan penyakit periodontal. Faktor lain seperti trauma, sikap dan karakteristik terhadap pelayanan kesehatan gigi, faktor sosio demografi serta gaya hidup juga turut mempengaruhi hilangnya gigi (Senjaya, 2016).

Hasil penelitian pengetahuan lansia tentang penyebab kehilangan gigi menunjukkan paling banyak yaitu dengan kategori kurang sebanyak 21 orang $(70 \%)$. Penelitian diatas sejalan dengan pe nelitian (Rezaaziza, 2021), dalam penelitiannya yang berjudul Gambaran Pengetahuan Warga Lansia Tentang Faktor Penyebab dan Dampak Kehilangan Gigi Tahun 2021 menyatakan bahwa warga lansia di Posyandu Lansia Desa Wonocoyo Kecamatan Panggul Kabupaten Trenggalek tentang faktor penyebab dan dampak kehilangan gigi tahun 2021 termasuk dalam kategori kurang. Hal yang memungkinkan terjadinya kurangnya pengetahuan tentang penyebab kehilangan gigi yaitu menurunnya daya tangkap informasi yang diperoleh dan belum pernah mendapatkan penyuluhan dari petugas kesehatan sekitar tentang kehilangan gigi serta faktor penyebab dan dampaknya. Informasi yang diperoleh baik dari pendidikan formal maupun nonformal dapat memberikan pengaruh jangka pendek (immediate impact) sehingga menghasilkan perubahan atau peningkatan pengetahuan (Notoatmodjo, 2010).

Hasil penelitian terhadap pengetahuan lansia tentang dampak kehilangan gigi menunjukkan paling banyak yaitu dengan kategori kurang sebanyak 15 orang $(50 \%)$. Penelitian ini sejalan dengan penelitian (Rezaaziza, 2021), dalam penelitiannya yang berjudul Gambaran Pengetahuan Warga Lansia Tentang Faktor Penyebab dan Dampak Kehilangan Gigi Tahun 2021 menyatakan bahwa warga lansia di Posyandu Lansia Desa Wonocoyo Kecamatan Panggul Kabupaten Trenggalek tentang faktor penyebab dan dampak kehilangan gigi tahun 2021 termasuk dalam kategori kurang. Hal yang memungkinkan terjadinya kurangnya pengetahuan tentang dampak kehilangan gigi yaitu jika kondisi kehilangan gigi dibiarkan berlanjut maka akan mengakibatkan dampak yang buruk bagi kesehatan. Dampak sistemik yang disebabkan oleh kehilangan gigi dapat berupa penyakit kardiovaskular, osteoporosis, dan peyakit gastrointestinal seperti kanker esofagus, kanker lambung, dan kanker pankreas. Keseimbangan terhadap konsumsi makanan inilah yang dapat berakibat pada timbulnya penyakit tesebut (E. Gusti Sigar Maulana et al., 2016).

Hasil penelitian terhadap kehilangan gigi pada lansia didapatkan bahwa jumlah lansia yang kehilangan gigi lebih banyak yaitu sebanyak 10 orang dengan jumlah kehilangan gigi 6-10 gigi yang hilang 
dan total kehilangan gigi sebanyak 74 gigi hilang $(33,3 \%)$. Penelitian ini tidak lebih baik dari penelitian (Noviani et al., 2020), dalam penelitiannya yang berjudul Kehilangan Gigi Pada Ibu Usia 30-60 Tahun Di Pengajian Karang Tengah Rt 005/03 Lebak Bulus Cilandak Jakarta Selatan menyatakan bahwa responden yang memiliki kehilangan gigi $\leq 3$ gigi sebanyak 30 orang $(75 \%)$. Banyaknya lansia yang sudah mengalami kehilangan gigi dikarenakan kurangnya menjaga kebersihan gigi dan mulut, serta banyak yang mengalami lubang gigi yang tidak dilakukan perawatan lebih lanjut. Kehilangan gigi merupakan penyebab terbanyak menurunnya fungsi pengunyahan. Kehilangan gigi juga dapat mempengaruhi rongga mulut dan kesehatan umum sehingga akan mempengaruhi kualitas hidup seseorang secara keseluruhan. Kehilangan gigi dapat disebabkan oleh berbagai hal, penyebab terbanyak kehilangan gigi adalah akibat buruknya status kesehatan rongga mulut, terutama karies dan penyakit periodontal (Ratmini \& Arifin, 2011).

Hasil penelitian pengetahuan tentang penyebab kehilangan gigi terhadap kejadian kehilangan gigi pada lansia paling tinggi yaitu kategori kurang sebanyak 8 orang dengan jumlah kehilangan gigi 6-10 gigi $(26,7 \%)$. Penelitian ini sejalan dengan penelitian (Anshary, Cholil, 2014), dalam penelitiannya yang berjudul Gambaran Pola Kehilangan Gigi Sebagian Pada Masyarakat Desa Guntung Ujung Kabupaten Banjar menyatakan bahwa. Hal ini kemungkinan disebabkan karena responden tidak mengetahui akibat efek kumulatif dari faktor penyakit gigi dan mulut seperti gigi berlubang dan penyakit periodontal adalah penyebab dari hilangnya gigi. Terlihat dari jawaban responden yang sudah selesai mengisi lembar kuesioner, sebagian besar responden salah mengisi kuesioner pada nomor 1, 4, 6, 8, dan 10. Kehilangan gigi disebabkan oleh faktor penyakit seperti karies dan penyakit periodontal. Faktor bukan penyakit seperti gaya hidup dan faktor sosio-demografi seperti umur, jenis kelamin, tingkat pendidikan juga berpengaruh terhadap kehilangan gigi. kehilangan gigi meningkat seiring seiring dengan bertambahnya usia akibat efek kumulatif dari karies dan penyakit periondontal (Siagian, 2016).

Hasil penelitian pengetahuan tentang dampak kehilangan gigi terhadap kejadian kehilangan gigi pada lansia paling tinggi yaitu kategori kurang sebanyak 8 orang $(26,7 \%)$ dengan jumlah kehilangan gigi 6-10 gigi yang hilang, dan paling rendah yaitu dengan kategori baik sebanyak 1 orang $(3,3 \%)$ dengan tidak ada gigi yang hilang. Penelitian ini sejalan dengan penelitian Anshary dkk, 2014. Hal ini (C) Jurusan Keperawatan Gigi Poltekkes Kemenkes Jakarta I J1. Wijaya Kusuma No. 47-48 Cilandak Jakarta Selatan, Indonesia email: jdht@poltekkesjakarta1.ac.id kemungkinan faktor usia memengaruhi daya ingat lansia, karena semakin tua daya tangkap seseorang akan semakin menurun. Usia mempengaruhi gaya tangkap dan pola pikir seseorang. Semakin bertambah usia akan semakin berkembang pula daya tangkap dan pola pikirnya sehingga pengetahuan yang diperolehnya semakin membaik (Retnaningsih, 2016). Umur mempengaruhi terhadap tingkat keparahan hilangnya gigi karena semakin meningkatnya umur maka resiko terkena karies dan penyakit periodontal yang menyebabkan hilangnya gigi akan meningkat (Anshary, Cholil, 2014).

\section{Kesimpulan}

Bedasarkan hasil diatas, dapat disimpulkan sebagai berikut:

1. Gambaran kehilangan gigi berdasarkan karakteristik usia menunjukkan paling banyak yaitu kelompok usia 60-69 tahun sebanyak 22 orang $(73,3 \%)$.

2. Gambaran pengetahuan tentang penyebab kehilangan gigi pada lansia paling banyak yaitu dengan kategori kurang sebanyak 21 orang (70\%).

3. Gambaran pengetahuan tentang dampak kehilangan gigi pada lansia paling banyak yaitu dengan kategori kurang sebanyak 15 orang (50\%).

4. Gambaran kehilangan gigi pada lansia yang lebih banyak yaitu sebanyak 10 orang dengan jumlah kehilangan gigi 6-10 gigi yang hilang dan total kehilangan gigi sebanyak 74 gigi hilang $(33,3 \%)$.

5. Gambaran pengetahuan tentang penyebab kehilangan gigi terhadap kejadian kehilangan gigi pada lansia paling tinggi yaitu kategori kurang sebanyak 8 orang dengan jumlah kehilangan gigi 6-10 gigi $(26,7 \%)$.

6. Gambaran pengetahuan tentang dampak kehilangan gigi terhadap kejadian kehilangan gigi pada lansia paling tinggi yaitu kategori kurang sebanyak 8 orang dengan jumlah kehilangan gigi $6-10$ gigi yang hilang $(26,7 \%)$.

\section{Saran}

Berdasarkan hasil penelitian ini, saran yang dapat peneliti berikan sebagai berikut :

1. Bagi responden diharapkan lebih meningkatkan kebersihan gigi dan mulut sehingga dapat mencegah atau mengurangi resiko terjadinya kehilangan gigi.

2. Bagi responden yang memiliki gigi hilang disarankan untuk menggunakan gigi palsu atau 
protesa untuk mengembalikan fungsi gigi seperti semula.

\section{Daftar Pustaka}

Anshary, Cholil, I. W. A. (2014). Gambaran Pola Kehilangan Gigi Sebagian Pada Masyarakat Desa Guntung Ujung Kabupaten Banjar. II(2), 138-143.

E. Gusti Sigar Maulana, Adhani, R., \& Heriyani, F. (2016). Faktor yang mempengaruhi kehilangan gigi pada usia 35-44 tahun di kecamatan juai kabupaten balangan. Dentino, 1(1), 98-103.

Notoatmodjo, S. (2010). Ilmu perilaku kesehatan. Jakarta: Rineka Cipta.

Noviani, N., Anggreni, E., Barus, A., \& Fanan, M. R. (2020). Kehilangan Gigi Pada Ibu Usia 30 - 60 Tahun Di Pengajian Karang Tengah Rt 005/03 Lebak Bulus Cilandak Jakarta Selatan. JDHT Journal of Dental Hygiene and Therapy, 1(2), 35-39.

Ratmini, N. K., \& Arifin. (2011). Hubungan kesehatan mulut dengan kualitas hidup lansia. In Jurnal Ilmu Gizi (Vol. 2, Issue 2, pp. 139147).
Retnaningsih, R. (2016). Hubungan Pengetahuan Dan Sikap Tentang Alat Pelindung Telinga Dengan Penggunaannya Pada Pekerja Di Pt. X. Journal of Industrial Hygiene and Occupational Health, 1(1), 67.

Rezaaziza. (2021). Pengetahuan faktor penyebab dan dampak kehilangan gigi pada warga lansia di trenggalek (Vol. 1, Issue 1).

Rizkillah, M. N., Isnaeni, R. S., Putri, R., \& Fadilah, N. (2019). Pengaruh kehilangan gigi posterior terhadap kualitas hidup pada kelompok usia 4565 tahun. 3(1), 7-12.

Satria Wardhana, G., Baehaqi, M., \& Amalina, R. (2015). Pengaruh Kehilangan Gigi Posterior Terhadap Kualitas Hidup Individu Lanjut Usia Studi Terhadap Individu Lanjut Usia Di Unit Rehabilitasi Sosial Pucang Gading Dan Panti Wredha Harapan Ibu Semarang. ODONTO: Dental Journal, 2(1), 40.

Senjaya, (2016). (2016). Gigi lansia. Jurnal Skala Husada, 13(1), 72-80.

Siagian, K. V. (2016). Kehilangan sebagian gigi pada rongga mulut. E-CliniC, 4(1). 